\title{
BOTTLENECK ANALYSIS IN MDF-PRODUCTION BY MEANS OF DISCRETE EVENT SIMULATION
}

\author{
Penker, A. ; Barbu, M. C. ${ }^{* *} \&$ Gronalt, M. $^{* * *}$ \\ * Kompetenzzentrum Holz GmbH, Wood Carinthian Competence Center, \\ Klagenfurterstr. 87-89, 9300 St.Veit/Glan, Austria \\ *** Transilvania University of Brasov; Facultatea de Industria Lemnului, \\ Str.Colina Universitatii nr. 1, 500084 Brasov, Romania \\ ${ }^{* * *}$ University of Natural Resources \& Applied Life Sciences, Feistmantelstr. 4, 1180 Vienna, Austria \\ E-Mail: a.penker@kplus-wood.at; cmbarbu@unitbv.ro; manfred.gronalt@boku.ac.at
}

\begin{abstract}
Material flow analysis by means of discrete event simulation proved to be a useful tool for decision support by several studies. This case study presents a bottleneck analysis for an Austrian Medium Density Fibreboard (MDF) production plant. The developed model was linked to actual production data and animated. The aim was to picture production, storage and transporting processes from the hot pressing of the boards through to shipping of batched costumer orders with sufficient accuracy. Different scenarios representing varying production programs and warehouse allocation principles were simulated. The results of the reference scenario showed good alignment to the corresponding factory data. At a production program with increased share of cut-to-size panels the saw turned into a bottleneck and the utilisation of the finished goods warehouse increased significantly.

The simulation provided useful information about the capability of the production, transport and storage systems and their performance at altered conditions.

(Extended paper from the $17^{\text {th }}$ International DAAAM Symposium, Vienna, Austria, 8-11 November 2006.)
\end{abstract}

Key Words: Medium Density Fibreboard, Discrete Event Simulation, Material Flow Analysis, In-Process-Storage Capacity, Warehouse Utilisation

\section{INTRODUCTION}

The European wood based panel industry uses production lines with a high degree of automation [1]. However especially in MDF-production the high variety of products and the huge volume of the boards may cause logistical problems in handling and storage of finished goods.

Standard analytical techniques make use of extensive mathematical models which require assumptions and restrictions to be placed on the model. This can result in a preventable inaccuracy in the output data. Simulations avoid placing restrictions on the system and also take random processes into account. In fact in some cases simulation is the only practical modelling technique applicable [2].

Simulation models are widely used to describe the technical performance of the material [3]. Material flow analysis as a tool for decision support in logistical issues was used before in other industries like steel manufacturing [4]. In particleboard processing simulation was applied to evaluate the material flow in the process of coating to support the decision whether it is necessary to invest in additional capacity or not [5].

This paper presents a bottleneck analysis for an Austrian MDF production plant by means of discrete event simulation. In contrast to particleboard plants the investigated MDFproduction uses an additional inventory for the conditioning of the boards. A simulation 
model for the discrete part of MDF board production was developed and linked with actual production data. Different scenarios were analysed to acquire information for tactical and strategic planning.

\section{METHODOLOGY AND DATABASIS}

The material flow considered starts with the continuous hot pressing of MDF-boards, proceeds with the cooling, conditioning, sanding, eventually cutting to size, and ends up with the storage and loading of batched customer orders on trucks and railway carriages. Fig. 1 shows a simplified chart of the material flow in the considered system. The major processes in this production line are continuous press, sander and cut-to-size saw.
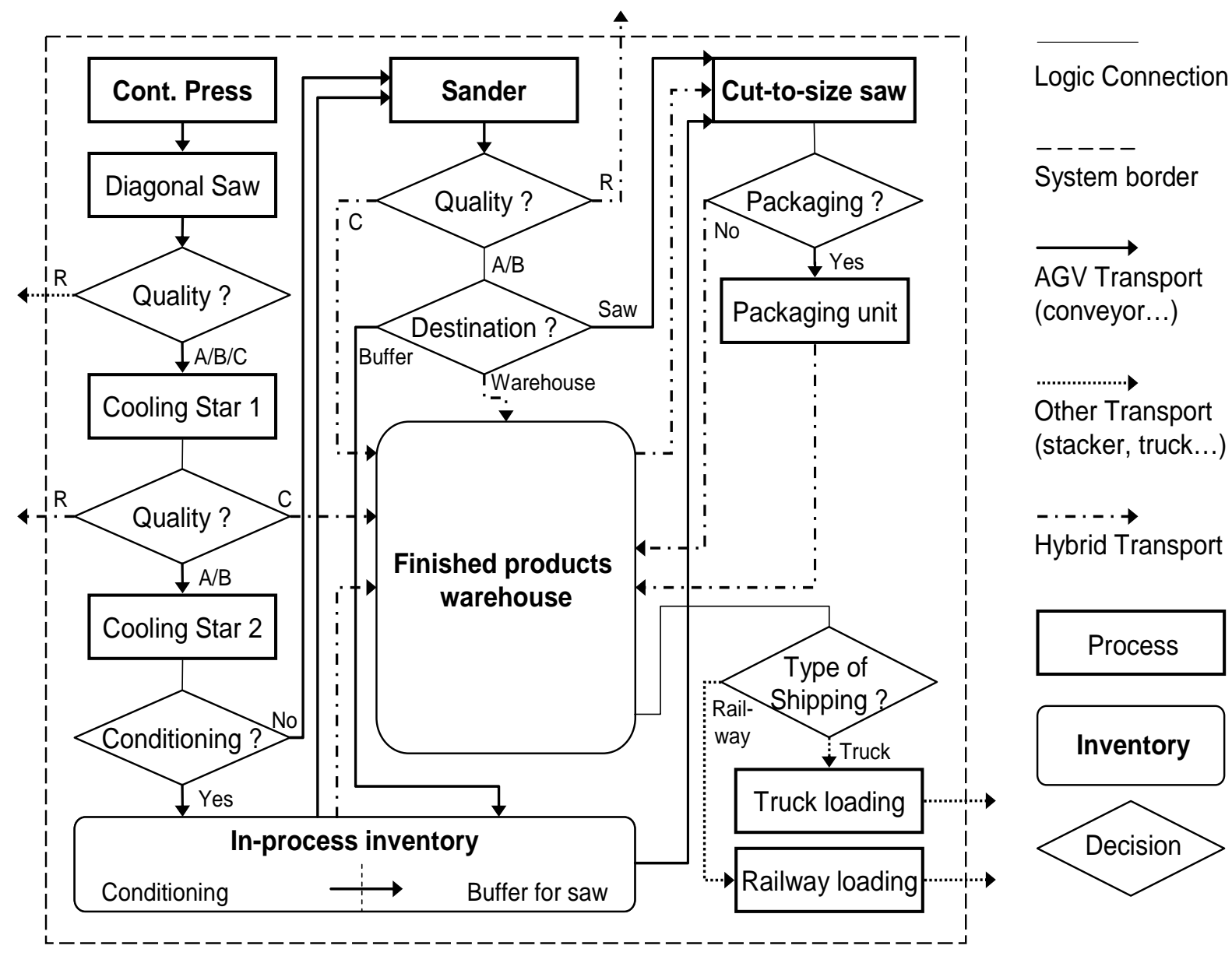

Figure 1: Flow chart of the considered system.

Quality control and grading appears at different stages of the production line. Quality A declares first-grade MDF boards. Product with minor defects is classified as Quality B. Grade $\mathrm{C}$ subsumes material which is usually utilised for packaging. Boards which show serious defects are recycled $(\mathrm{R})$ and therefore they don't have to be considered in the model.

The in-process inventory is divided into two different areas, whereas conditioning has priority. The inventory is also used as a buffer for the saw when orders can not be processed directly. In case of overload of the in-process inventory the finished products warehouse exceptionally is used as a buffer for the saw. 


\subsection{Problem description - Scenarios}

Two main issues were analysed in detail: The first one deals with the alteration of the finished products warehouse and its effect on the utilisation of the warehouse and the transporters used for batching loads and loading of trucks and carriages. This rebuild includes both an increase of storage area and the construction of an extended railway track into the warehouse in order to speed up the loading of customer orders by reducing the average transport distance. However the number of loading stations for trucks is reduced in this case. In connection with that, new warehouse allocation principles were evaluated and proposed.

The second issue was to work out the effects of changes in the production program on the two inventories and on transporters and process utilisation as well. More precisely the effect of a shift in the production program to a higher percentage of thin boards on one hand and to an increased proportion of boards passing the cut-to-size saw on the other hand was analysed.

The two different warehouse situations and the three production programs resulted in six distinctive scenarios (Table I). Scenario 1 was used as a reference scenario to compare to the other scenarios and to actual factory data.

Table I: Scenario - Matrix.

\begin{tabular}{|c|c|c|c|}
\hline & \multicolumn{2}{|c|}{ Finished products warehouse } \\
\hline & & common & extended \\
\hline \multirow{3}{*}{ 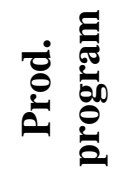 } & common production & 1 (reference) & 1.1 \\
\hline & increased amount of thin boards & 2 & 2.1 \\
\hline & increased cutting to size & 3 & 3.1 \\
\hline
\end{tabular}

\subsection{Research method and factory data analysis}

For the simulation analysis the process oriented software Arena 8.01 was used. It allows a very flexible design of the model using a variety of modules [6]. Modelling in Arena is based on discrete event simulation and stochastic components [7].

As input for the numerical experiments factory data covering one year was used. Among others following data was taken into account: material flow, process intersections, product specifications, process parameters depending on the product and season, characteristics of storage, order picking and shipping. In addition events of failure like repairs, accidental stops and maintenance with the frequencies and durations according to the records for each process have been implemented.

By means of regression analysis and statistical distributions it was possible to describe the processes of production, transport and storage with sufficient accuracy. As an example Fig. 2 shows the calculation of the continuous press throughput depending on board type, thickness and size.

The polynomial function shows adequate conformance to the factory data $\left(\mathrm{R}^{2}=0,97\right)$. Expressions like this where implemented into the model to characterise the throughput of the continuous press and other processes depending on the board type and dimension. 


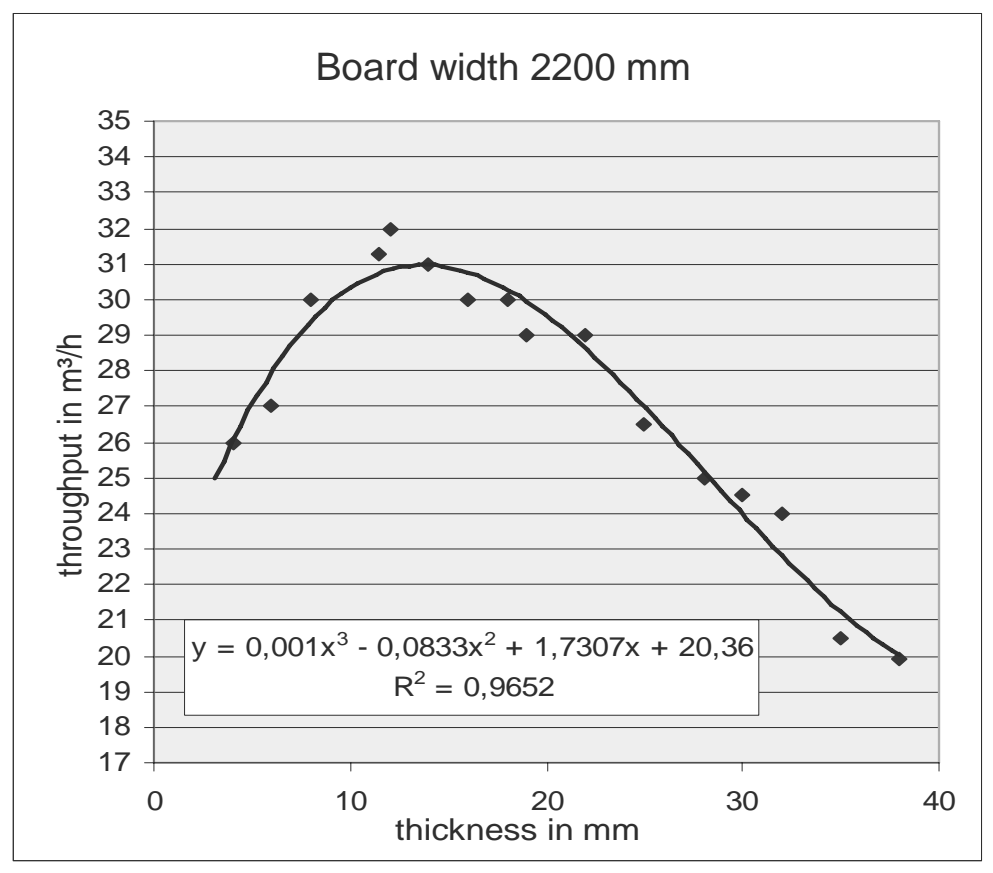

Figure 2: Calculation of hot-press throughput for Standard-MDF in the model.

For characterisation of quality proportions and loading weights the Arena Input Analyser was used. This tool analyses a dataset and identifies the best fitting continuous function on basis of the minimum Square Error. An example is shown in Fig. 3. In this case the Beta function shows the lowest square error which can also be seen in the good fit between the curve $(14 * \operatorname{beta}(0.252,3.99))$ and the histogram of real data.

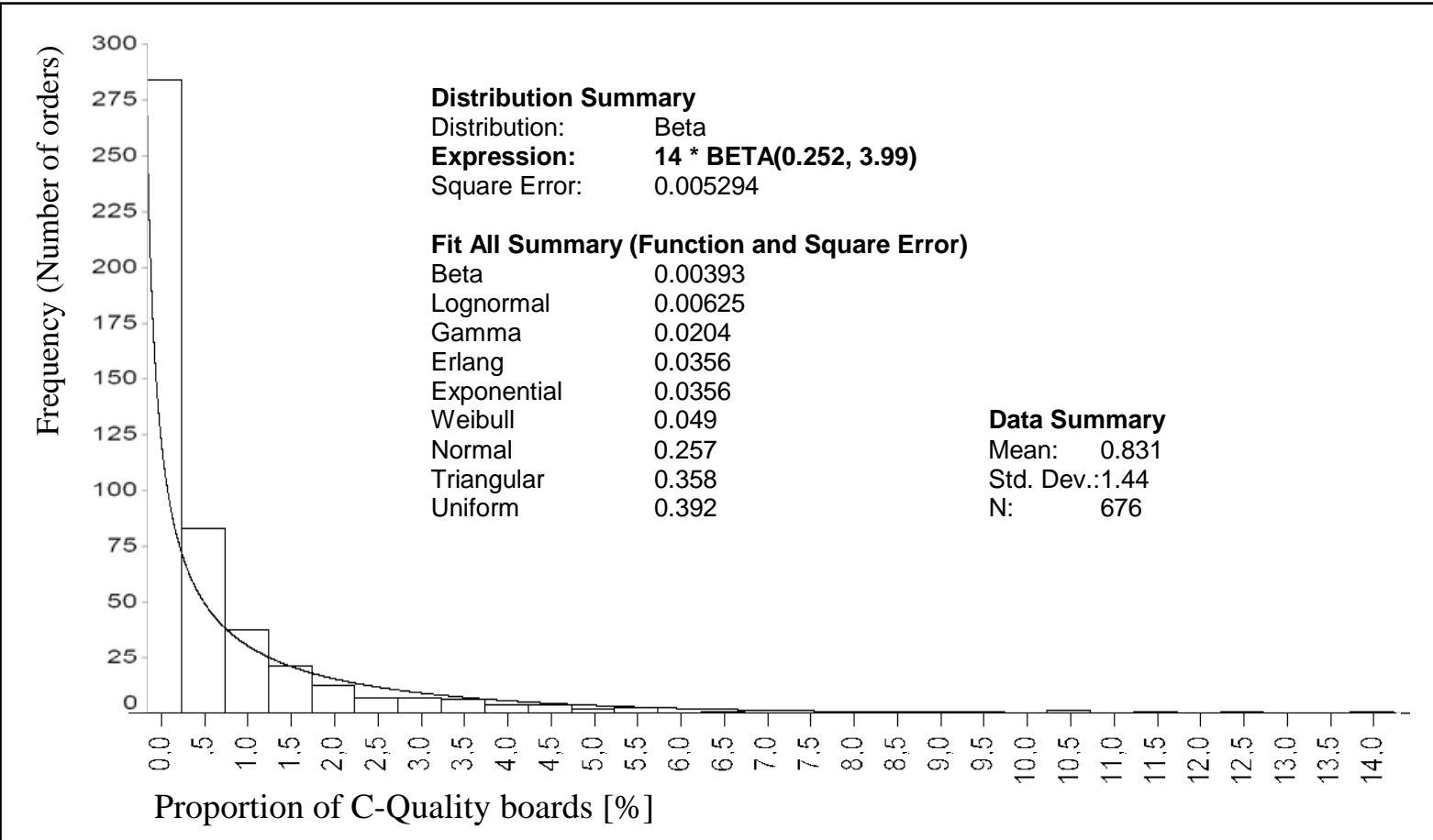

Figure 3: Histogram of the proportion of third Quality boards per order at the sander. 


\subsection{The simulation model: Logic and animation}

The main challenge in the modelling phase was the creation of the logic for the two inventories. The key - function of the in-process inventory is the conditioning of the MDF boards to improve their properties. The conditioning time is dependent on the type and thickness of the boards. A batch of $18 \mathrm{~mm}$ standard MDF e.g. has to mature (conditioning in pile) for at least 48 hours to proceed to the sander. In addition the sequence of jobs at the sander has to be such that the number of sanding belt replacements is minimised. Varying portions of the storage area are used as a buffer between sanding and cutting to size. This is dependent on the needed space for conditioning which has priority. In this area two Automated Guided Vehicles (AGV's) are used for the carriage of boards. In the simulation model the exact distances in the transportation network, the speed of the AGV's and their loading and off-loading times were considered.

The logic of the finished products warehouse is of high complexity. First the company deals with more than 1200 products with varying dimensions and qualities at this stage and the feed-in of the product has to be in a way that a minimum of storage volume is occupied. In this area five stackers of varying capacity are used for transportation. Two are used for in-feed of MDF boards and three for batching customer orders and loading of trucks and railway carriages. In the system additional transport in form of conveyors occurs between the processes of pressing, cooling, conditioning, sanding and cutting-to-size. Beside capacity and speed, breakdowns and maintenance for all the transporters were taken into account to capture the system precisely.

Up to the warehouse the plant works 24 hours every day except for defined periods for maintenance which were considered in the model. Batching of orders and loading of trucks and railway carriages is performed only on workdays in two shifts. Some logic was constructed to capture this discontinuity, the process of batching orders for customers and the loading of goods. In addition seasonal influences on production and sales were integrated into the model. Fig. 4 depicts the fluctuation of shipping in different month. It is visible that in January the rate of loaded trucks per day is more than $17 \%$ higher than the annual average. In contrast August and December are periods of low loading intensity. Moreover the analysis of shipping documents proved that loading is also dependent on the weekday and the daytime.

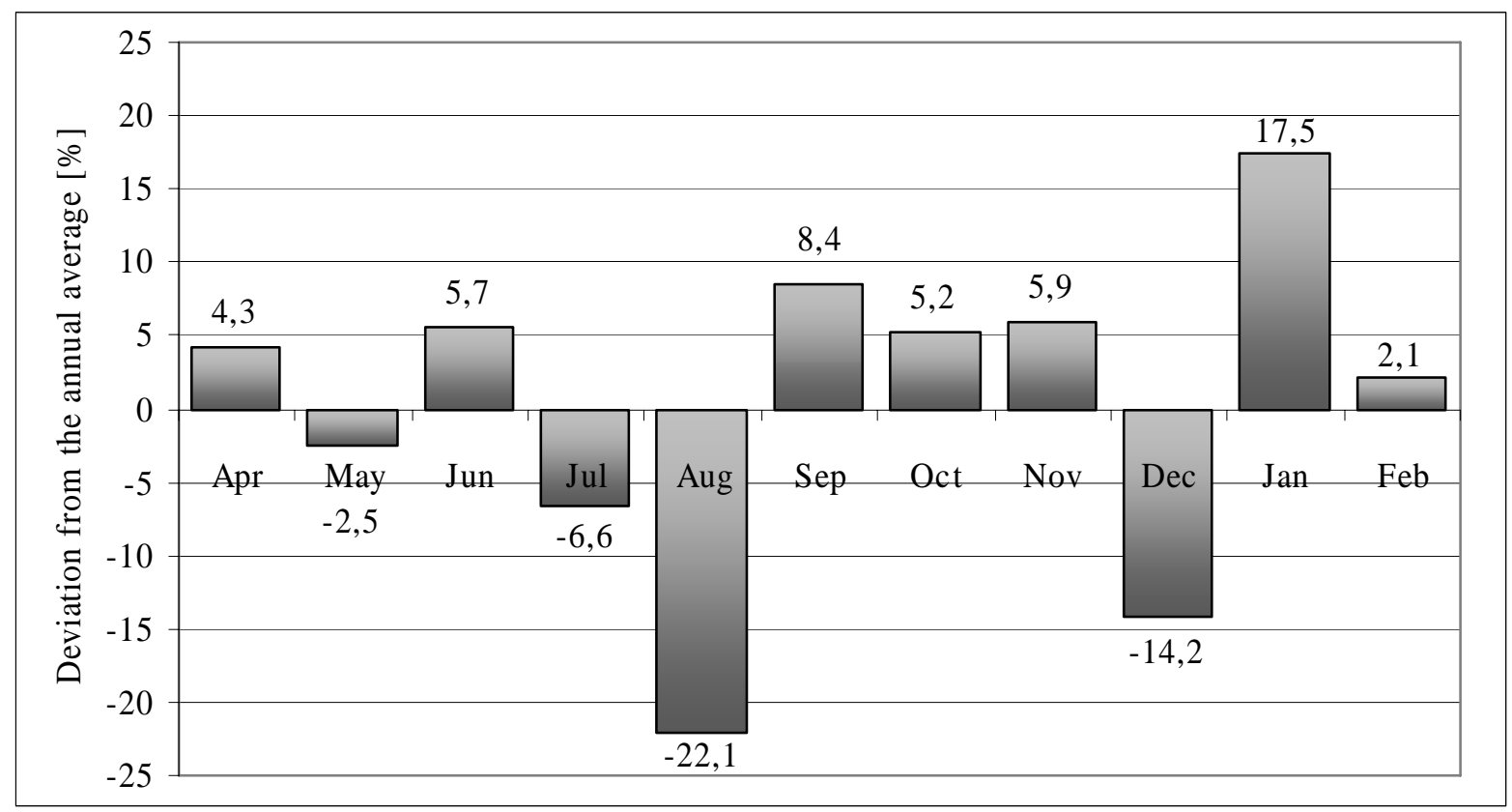

Figure 4: Monthly differences in the Number of truck loads per day. 
The model was then animated, proving a useful tool for the validation of the logic, the communication of the model and understanding of the system. A section of the animation is shown in Fig. 5. In the upper section of the screen shot a part of the in-process inventory with the automated transporters unit is visible. Beneath the sander and the stacking units are seen.

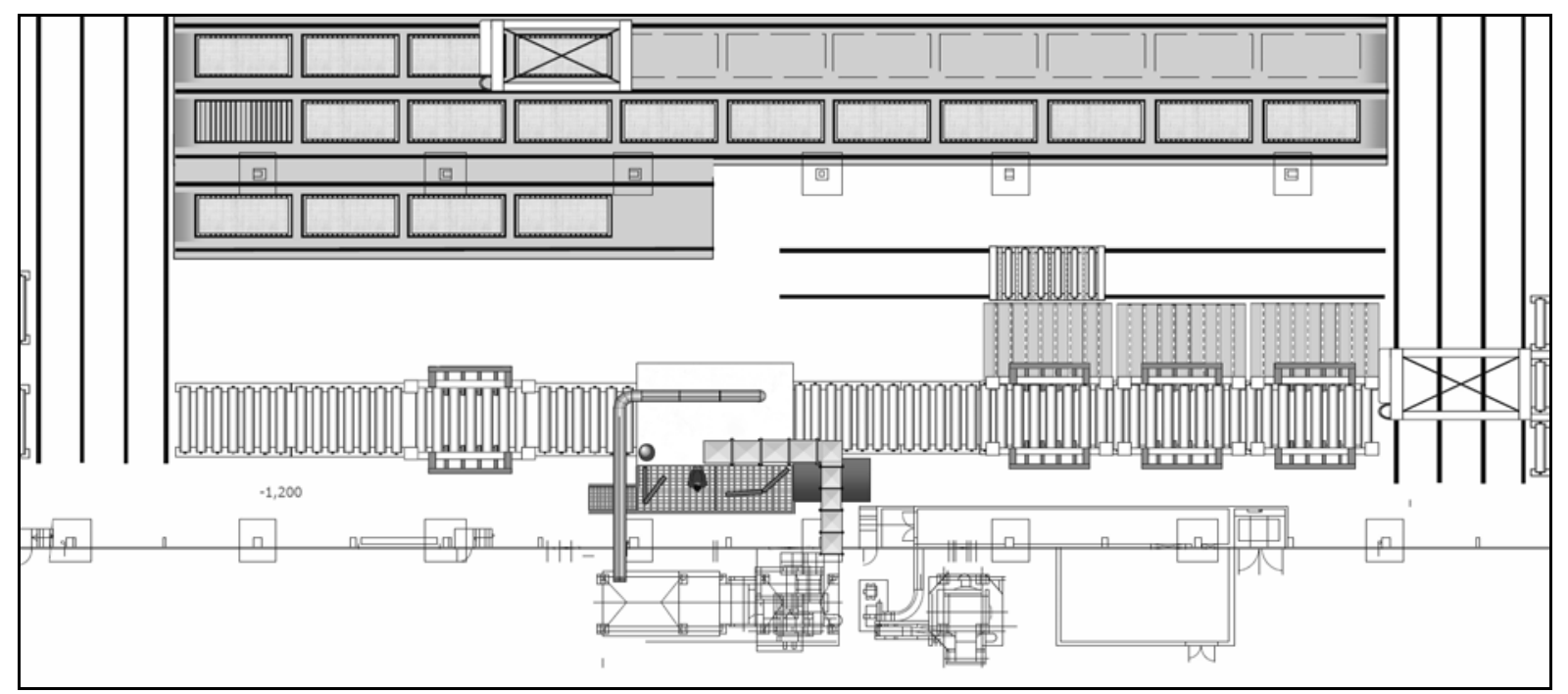

Figure 5: Partly image of the animated model: in-process inventory and sander.

The simulation run length was three month in each scenario. A preliminary warm up period of 72 hours was used to equalise starting effects. As initial inventory the data generated in the warm-up run was used.

\subsection{Validation and verification of the model}

For the model validation a comparison of the animation and the real system was used. So differences in the material flow were detected to adjust the model. For verification of the model results from the reference scenario where compared to real production data from the corresponding time span. Information like throughput, utilisation and failure time of processes and transporters were compared. The good alignment of the data is an indication of the ability of the model to picture the real system accurately [8].

\section{RESULTS AND DISCUSSION}

The key-results of the simulation experiments are covered in this section. In addition different scenarios are set in relation and the findings are discussed.

As expected the planned extension of the warehouse showed minor influence on the utilisation of continuous press, sander and cut-to-size saw as seen in Fig. 6. The press is also not influenced by the different production programs. The occupancy rate was 95 percent in each scenario. This process was effectively not idle, which means that the throughput of the press determines the throughput of the entire system.

The sander was 13 percent of the total time inactive (maintenance and repairs) which is not influenced by the scenario conditions. Compared to the reference the utilisation was increased by approximately five percent in the scenarios with higher amounts of thin boards (S2 \& S2.1). However the sander showed high portions of idle time in each scenario which proves that there is no risk of turning into a bottleneck. 
In contrast to the sander the utilisation of the saw is on a higher level. In the scenarios with a higher number of cutting-to-size orders (S3 \& S3.1) the idle time is reduced to approximately two percent. That implies that the flexibility at the saw is reduced to a minimum in these scenarios. If a serious break down appears or a further increase in cuttingto-size takes place the saw will turn into a bottleneck and the utilisation of the press will be reduced accordingly.

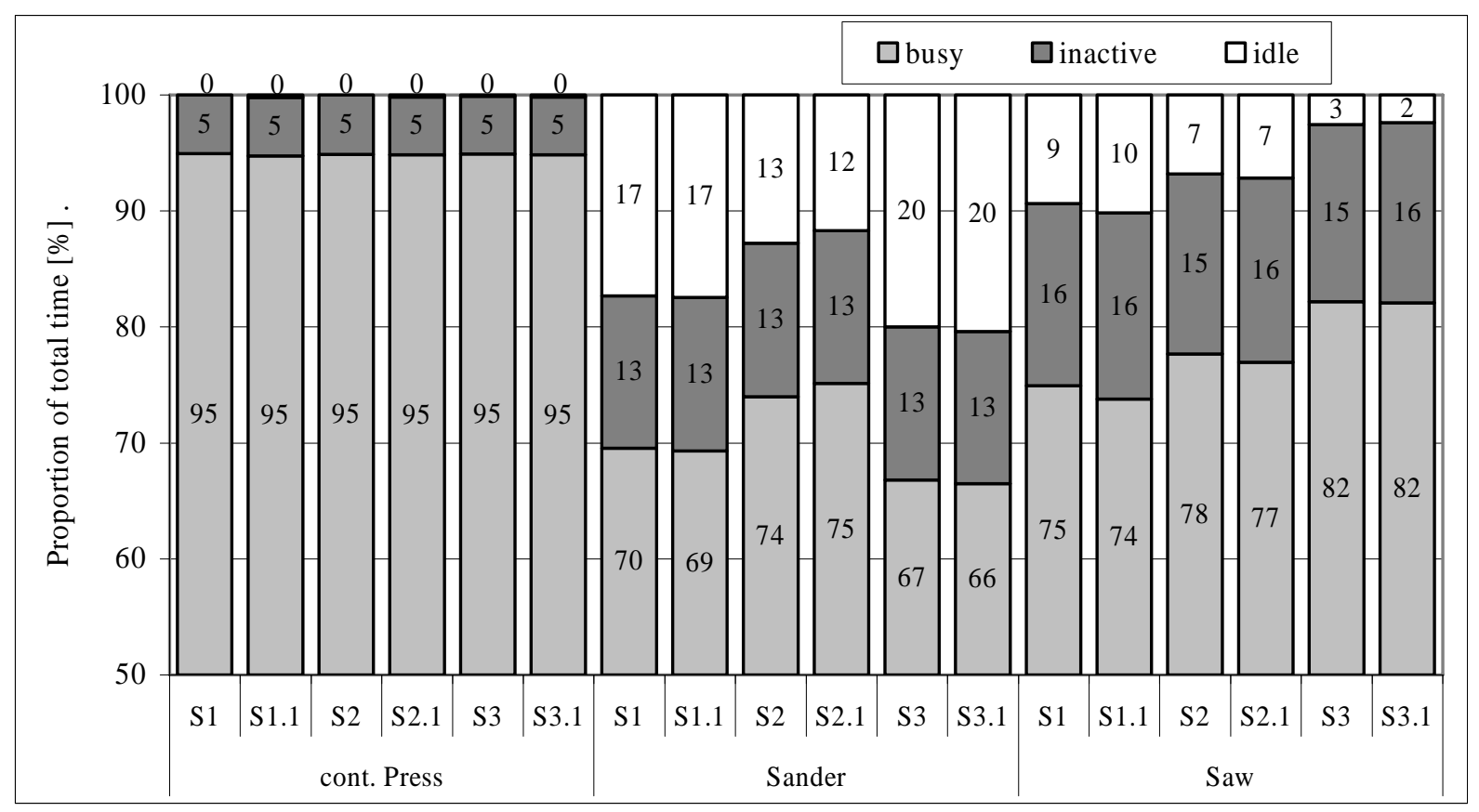

Figure 6: Utilisation and failure time of the main processes in different scenarios.

The alteration of the finished goods warehouse seems to have no significant effect on the transport systems and the in-process inventory. However the average occupancy rate of the extended warehouse was found to be reduced by 10 percent at common production and by seven and five percent respectively at a production program with increased amounts of thin boards or higher portions of cutting-to-size.

The effect of the production program on the warehouse utilisation is shown in Fig. 7. As expected the production of more small boards (S3 cut-to-size) leads to higher utilisation. Thin boards (S2) also occupy a lot of space whereas in relation common production (S1) leads to a discharge of the warehouse.

The double sawtooth-shaped curves obviously display the continuous feed-in of boards and the fluctuating process of loading. Shipment is shut down on the weekends and at night. Therefore every major peak marks a Monday morning when loading starts. It is followed by four small peaks which point out Tuesday to Friday morning.

The loading duration of railway carriages was found to be lower in the scenarios with extended warehouse, due to the lower transportation distances. On the other hand an increase of waiting time and loading duration for trucks in all scenarios compared to the reference scenario was discovered. It is comprehensible that higher amounts of thin and small boards lead to longer waiting and loading times. The negative influence of the extended warehouse is possibly described by the reduced number of loading stations and by the fact that in the new warehouse the loading space for railway carriages is positioned behind the truck loading stations. Due to this a carriage can only be loaded when no truck blocks the space. 


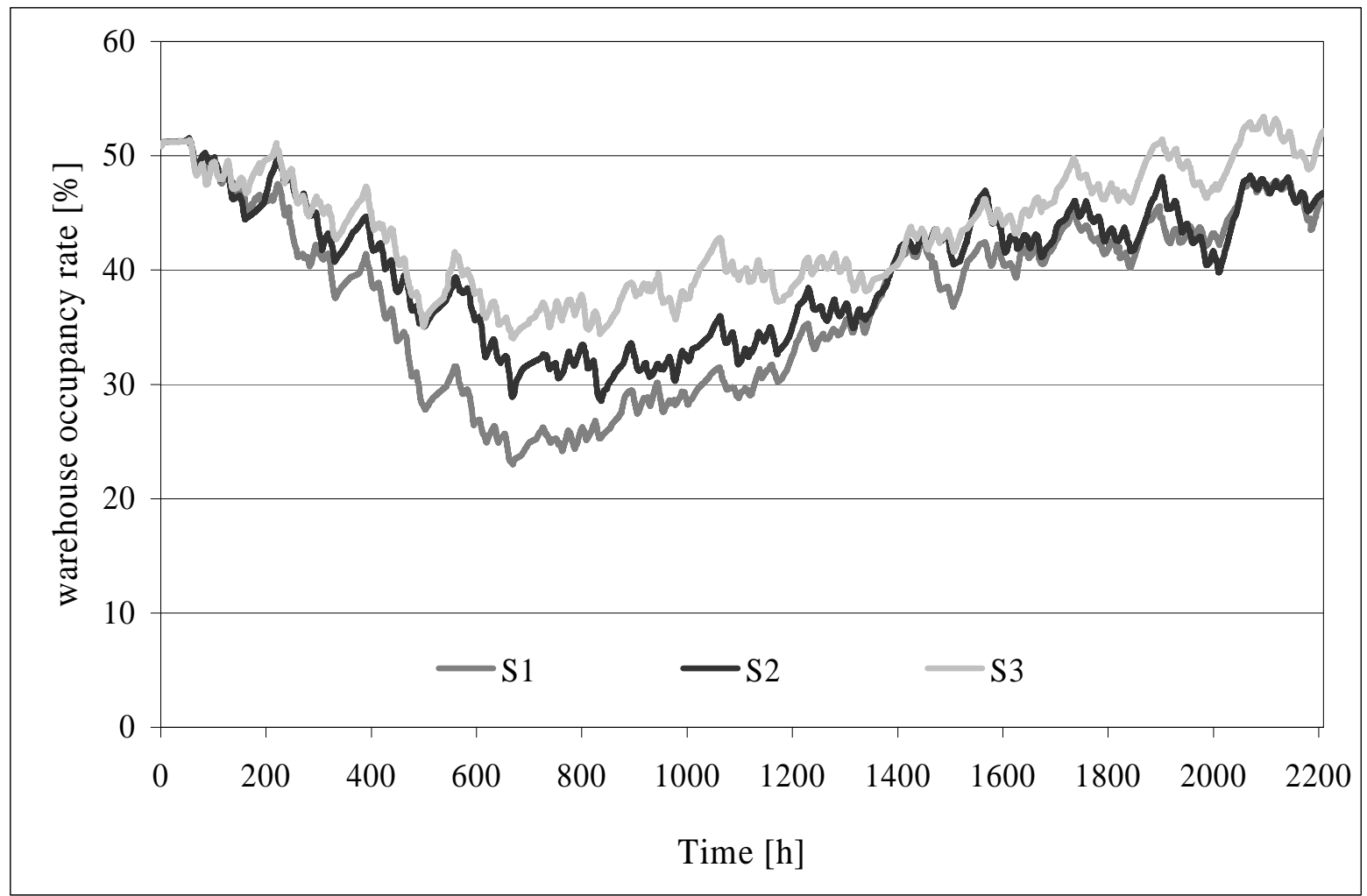

Figure 7: Warehouse utilisation at different production programs.

Furthermore if a loading station is blocked by a truck the following truck has to pick one of the adjacent stations which lead to increased loading distances and durations. The simulation showed that the loading space will be a bottleneck in the new warehouse. An increased production of thin or small boards aggravates the problem.

\section{CONCLUSION}

By means of discrete event simulation it was found out that the extension of the warehouse has a positive effect on the occupancy rate. Laying of the railway track into the warehouse leads to reduced loading duration for railway carriages. However the alteration of the warehouse implies a reduction in the number of truck loading stations, which increases the waiting and loading times for trucks.

In addition the simulation provided useful information about the capability of the production, transport and storage system and its performance at altered production programs and maximum load. It has been shown that the cut-to-size saw turns into bottleneck at a proportion of $68 \%$ of the produced boards passing the saw.

The Case Study showed that especially automated processes are an excellent scope for simulation experiments. A major drawback of this method is that simulation models can not be standardised. That means, if the structure of the real system changes the model has to be adjusted.

However one of the primary advantages of simulation experiments is that they are able to provide users with practical feedback when designing real world systems. The correctness and efficiency of different designs may be tested before the system is actually constructed. So incorrect planning can be avoided which saves expenses. 
Another benefit of simulators is that they permit to study a problem at several different levels of abstraction. By approaching a system at a higher level of abstraction, it is easier to understand the behaviours and interactions of all the high level components within the system and is therefore better equipped to counteract the complexity of the overall system.

Thirdly, the model can be used as an effective means for teaching or demonstrating. This is particularly true if a detailed animation exists. Such models dynamically show the behaviour and relationship of all the simulated system's components, thereby providing the user with a meaningful understanding of the system's nature.

Consequently simulation is an applicable tool for the analysis and assessment of advanced manufacturing, transport and storage systems in the wood based panel industry.

\section{REFERENCES}

[1] Gronalt, M.; Häuslmayer, H.; Teischinger, A. (2005). Mass Customisation in the Wood-Working Industry - Concepts for customised wooden floorings, Proceedings of International Mass Customisation Meeting, 163-174

[2] Biethahn, J. (Hrsg.) (2004). Optimierung und Simulation, Oldenbourg Wissenschaftsverlag, München

[3] Wu, Q.; Xiong, M. A Simulation of Moisture Diffusion Process in Furniture - Grade Medium Density Fibreboard, from http://www.rnr.lsu.edu/lfpdc/publication/present/woodscience/pdf/ MDFmoisturepaperjapannew.pdf, accessed: 2006-07-30

[4] Schmid, V. (2003). Materialflussanalyse bei der logistischen Beurteilung einer Ersatzinvestition, Diploma Thesis, Universität Wien, Vienna

[5] Benna, T. (2002). Der Einsatz von Simulation zur Materialfluss- und Kapazitätsanalyse am Beispiel der Spanplattenproduktion, Diploma Thesis, Universität Wien, Vienna

[6] Kelton, W. D.; Sadowski, R. P.; Sadowski, D. A. (2002). Simulation with Arena, McGraw - Hill, New York

[7] Banks, J.; Carson, J. S. I.; Nelson, B. L.; Nicol, D. M. (2000). Discrete-Event System Simulation, Prentice Hall, Englewood Cliffs NJ

[8] Carson, J. S. (2005). Introduction to Modelling and Simulation, Proceedings of the 2005 Winter Simulation Conference, 16-23 